\title{
Research on Cable-driven Robots
}

\author{
Yupeng Deng ${ }^{1}$, Long Bai1 ${ }^{1,}$, Zhang Long ${ }^{1}, J_{1 a n}$ Guan $^{1}$, Xiaohong Chen ${ }^{1}$, Junzhan Hou ${ }^{2}$, Wenbo Duan ${ }^{2}$ \\ ${ }^{1}$ State Key Laboratory of Mechanical Transmissions, Chongqing University, Chongqing, 400044, China \\ ${ }^{2}$ Xi'an Institute of Applied Optics, Xi'an, 710065, China. \\ ${ }^{*}$ Corresponding author
}

\begin{abstract}
Cable-driven mode has the advantages of low inertia, low noise, high accuracy and some other unique advantages in some occasions. Therefore, the application of cabledriving technology in robots is more and more extensive. Many researchers have also carried out in-depth researches and discussions on the cable-driven robots, and achieved fruitful results. This paper first summarizes the characteristics of the cable-driving technology. Then, describes the types of cable-driven mode. The application of cable-driven mode in camera robots, rehabilitation robots and transportation robots are introduced, and the technique of cable tension, motion modeling and control technology in the cable-driven robots are analyzed and summarized.
\end{abstract}

Keywords-Cable-driven robots; Tensioning technology; Motion modeling; Controlling technology; Development trend

\section{INTRODUCTION}

Robotics is a multidisciplinary discipline which developed in recent decades. Its emergence has brought a tremendous change in the traditional industrial production. The method of human production has come into a new era of information \& intelligence technology. Robot as a highly integrated product of mechanical and electronic, its research reflects the highest level of mechanical manufacturing, control technology, simulation analysis, new materials, image acquisition, etc. At present, robots have been widely used in military, industrial, aerospace, scientific exploration and many other fields. As one of the key driving methods in robot driving technology, cable-driving has become a hot topic since the development of 1940s and 1950s.

\section{CHARACTERISTICS OF CABLE-DRIVING TECHNOLOGY}

The common driving modes include mechanical driving, hydraulic driving, pneumatic driving, etc. Hydraulic cylinder and connecting rod have limited the motion range of the end of the body to some degree, which is the typical defect in traditional driving mode. To overcome the shortcomings of traditional mechanism manipulation methods, researchers have developed a new type of cable traction manipulation mechanism after analyzing many drive modes' features and attributes. The physical properties of the cable make it possible that one end of cable can be freely tightened or released, while the other end can make the end-effectors moving in a large space. The difference between a cable-driven robot and a conventional one is that it uses a cable rather than a rigid link to drive its own weight and load. It developed in the fifties of the last century and was firstly applied to the nuclear industry [1]. The motor and deceleration devices are all installed on the base of cable-driven robots, through the motor rotation to achieve tightening and releasing the cable, and through cables to pull the next joint to achieve long-range power transmission [2]. Compared with hydraulic, pneumatic, mechanical and motor driving mode, cable-driving has the traits of low noise, clean, no lubrication, shock absorption, easy installation and low maintenance costs. In addition, the cable-driving has several vital advantages: 1)The end of the actuator has high speed and acceleration, especially suitable for high-speed occasions; 2)Cable has the characteristics of flexibility, high sensitivity, good security, is very suitable for rehabilitation training equipment; 3)Having high body quality-load rate, especially suitable for hoisting operations; 4)Poss essing large workspace, especially suitable for large-scale operation occasions; 5)Cable can disassembled easily, it's very suitable for rapid as sembly occasion[3].

The above features make cable driving in many forcetransmission systems more suitable than other transmission methods, especially in the requirements of small size, light weight and low noise occasions. Based on the characteristics of cable traction mechanism with the flat working space and fast moving speed, cable driving has wide applications in camera robot, medical rehabilitation robot, large radio telescope, aeros pace, coordinate measurement, giant ship manufacturing, as sembly robot, crane, virtual reality feedback devices, etc.

\section{ClASSIFICATION OF CABLE-DRIVEN ROBOT S}

Cable-driven mechanism of manipulator is made up of bar and motion part. And a variety of structures are designed to meet different job demands. These structures are basically divided into series structure, parallel structure and mixed structure. Series and parallel mechanis $m$ have wider applications in cabledriven robots.

Cable-driven series robots have two forms: 1) A transmission manipulator drives one degree of freedom. The rope forms a closed loop on the pulley, and the motion is transmitted by friction. 2) One end of cable is connected to manipulator and the other end is connected directly to the connecting rod. This structure does not require preload [4].Cable-driven tandem robots are mainly used in dexterous hands, legged robots or a small space which need to avoid obstacles. But series cantilever structure is poor in stiffness and positioning accuracy, etc.

Cable-driven parallel robot means to use cable instead of connecting rod as driving element. The parallel mechanism has the characteristics of high rigidity, low weight, high load capacity, no error accumulation, etc. Meanwhile, it has high position accuracy and less energy consumption. But the work space is small. Cable-driven parallel robots combine the advantages of parallel mechanis $m$ and cable driving technology, not only have high stiffness, high precision and high load 
capacity, but also with low weight. At present, many scholars are mainly studying on the cable-driven parallel robot. The characteristics of the cable-driven series robots and the parallel robots are shown in table I.

T ABLE I. COMPARISON OF THE CHARACTERRIST ICS OF CABLEDRIVINGSERIES ROBOT S AND PARALLEL ROBOT S [5]

\begin{tabular}{c|c|c}
\hline Category & Series robots & Parallel robots \\
\hline Stiffness & Poor & Good \\
\hline Carrying capacity & Low & High \\
\hline Motion positioning & Open loop & Closed loop \\
\hline Working space size & Large & Small \\
\hline Positioning error & Cumulative & Average \\
\hline Control technology & Easy & Difficult \\
\hline Modeling simulation & Easy & Difficult \\
\hline
\end{tabular}

\section{REVIEW OF CABLE-DRIVEN ROBOTS}

\section{A. Review of Cable-driven Camera Robots}

The application of cable driving is most mature in cable traction camera system. The cable-driven camera systemcan be divided into planar motion cable-driven camera system and allround movement cable-driven camera system. The former is the cable camera carrying system, which can not only effectively keep balance and compensate the shooting angle and the lack of regional, but also expand the shooting field of vision. The latter can expand the scope of the camera systemfrom the field of view and improve shooting flexibility, with a smart, unlimited rotate lens [6].

The most representative camera robots are Skycam [7] and Spidercam [8]. The August Design company developed the Skycam camera robot (Fig.I A), which can move and locate quickly, and provide almost any location and angle for the camera system. Germany's Spidercam (Fig.I B) uses a standardized and reliable component module that can move the camera horizontally or vertically, and provide complete threedimensional motion. These two camera robots can not only realize hovering, but also get to anywhere in the venue flying in reachable range, and without the arm length restrictions. The mechanical structure is also simple and removable, flexible to application.

In addition, Australian National University applied cable transmission to a number of smart detectors and imaging tracking device [9-10](HyDrA) (Fig. I C), due to bevel-gear type cable transmission, it has more compact structure, wider rotation range, bigger maximum angular velocity and higher corner resolution. With ingenious drive systemdesign for CeDAR(Fig.I D), which makes the system maximize the load capacity, and improves the system's angular resolution rate and repeat positioning accuracy, and can guarantee the system has high dynamic characteristics.

CAMCAT's cable camera system has good reliability and work results [11], (Fig.I E, Fig.I F) which has a wide application in sports events, entertainment, documentary etc. The design of cable system is based on the modular structure. CAMCAT did not study the camera platform, but its products can be equipped with a variety of camera platforms. The base car runs on two high-strength fiber cables, which can be fitted with multiple loads, and the additional modules are powered by the battery packed on the cart [12].

Cable-cam Sweden AB company designed EagleCam (Fig. I G). EagleCam is a two-dimensional cableway camera system, which can be equipped with a common camera platform. Its maximu moving speed is up to $100 \mathrm{~km} / \mathrm{h}$, the maximum length of the body is $1000 \mathrm{~mm}$ and its weigh is about $18 \mathrm{~kg}$. The camera system has an advanced positioning system, even if the camera robot beyond the sight, can also accurately determine the location. The company also developed a single cable camera system, called Cabledolly, which is easy to operate, (Fig.I H), mainly for low-speed sports scenes or limited space in the sports space [13].

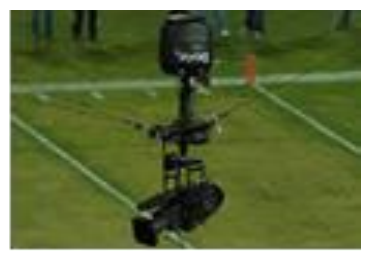

(A)

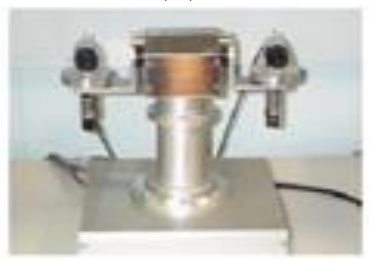

(C)

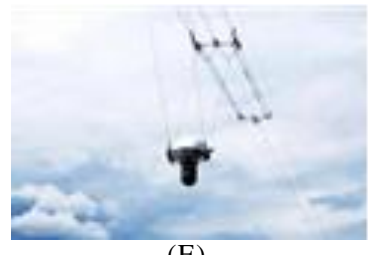

(E)

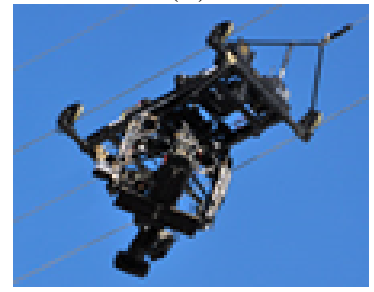

(G)

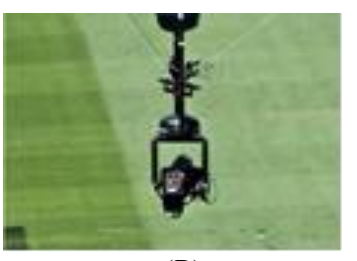

(B)

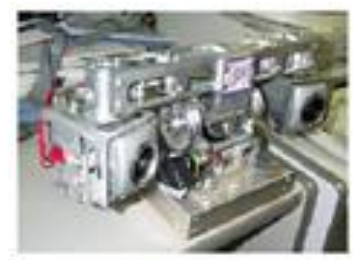

(D)

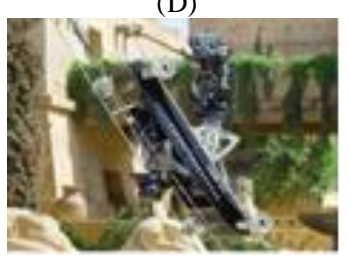

(F)

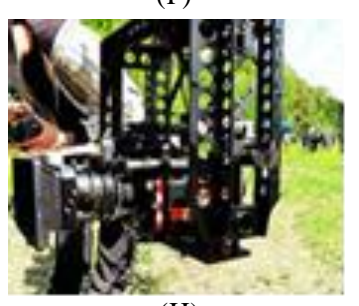

(H)
FIGURE I. EXAMPLES OF CABLE-DRIVEN CAMERA ROBOTS: (A). SKYCAM SYSTEM. (B).SPIDERCAM SYSTEM. (C)HYDRA. (D)CEDAR (E) CAMCAT 2D. (F)CAMCAT VERTICAL. (G)EAGLECAM (H) CABLEDOLLY

The emergence of camera robots not only opens up a new form of interactive viewing, but also greatly reduces the workload and work difficulty of photographers. However, due to the camera robot is hanging in the air, and non-rigid characteristics of the cable, if the camera robot moves in highspeed or on some adverse conditions, it will have a great impact on the photographic effects. Therefore, some scholars have optimized the cable tension distribution of the high-speed cable driving camera by considering the influence of the sag and 
inertia of the rope, to improve the stability of the camera robot in high speed motion or harsh condition [14].

\section{B. Review of Cable-driven Rehabilitation Robots}

With the emergence of population aging, the elderly population with various diseases and limb movement disorders increases rapidly. And physical injury caused by traffic accidents and accidental injuries often occur. Theoretical medicine and clinical medicine have proved that, except the neces sary surgical treatment and drug treatment, the correct and scientific rehabilitation training for the body movement function recovery also play a vital role. However, traditional artificial medical equipment for rehabilitation therapy has been far from meeting patients requirements. So, designing appropriate rehabilitation training equipment is urgent and necessary. The rehabilitation robots for rehabilitation therapy and functional training has brought greater benefits, and can reduce the burden of health care workers.

Lixun ZHANG proposed a cable-driven astronauts training robot based on the flexible Stewart platform [15] (Fig.II A), making the body under weightlessness, which can achieve virtual gravity loading control during the movement process. Weidong WANG et al designed a gravity balance device for pelvic rehabilitation [16] (Fig.II B), through six active rope traction simulated pelvic center of the four degrees of freedoms, through modifying the movement parameters to achieve training results. According to the actual situation of patients, Germany Rolfhofer Institute developed a cable-driven parallel rehabilitation robot [17] (Fig.II C). The robot uses multiple cables to control trainees' torso, supplemented by other ropes for measurements of torso motion. The robot can not only apply for the trainee in the balance training, but also achieve weight loss training. Runtian YU proposed a rope-driven parallel ankle joint rehabilitation robot [18] (Fig.II D), which has higher control accuracy and solves the problems that the rotation center does not match and rigid bar easily causes inertia impact.

Sunil K. Agrawal designed a wearable exoskeleton robot (Fig.II E) with six drive motors, through the cables drive the forearm of the upper limb to help patients with stroke or muscle tissue damage rehabilitation. Sai K. Banala designed a assisted gait training robot (Fig. II F) for stroke patients, which consisted of active exoskeleton and force field controllers, by limiting unwanted gait movement and assisting the required gait to increase the coordination of the knee and ankle in the shortdistance walking, and it also can increase the speed of training for patients on the treadmill [19]. Jones CL et al. proposed a 3DOF exoskeleton robot (Fig. II G) for the single-finger injury recovery, which can provide independent control of the required speed and torque [20]. Mao Y et al. designed a 5-DOF ropedriven upper limb rehabilitation robot (Fig.II H), aimed at the shortcomings of bulky and lack of overall level of rehabilitation training. This robot is suitable for power control, and the attachment of cables on the limb can be adjusted to achieve a larger work space. Simulation and experimental results show that power control can increase the effect of rehabilitation [21].

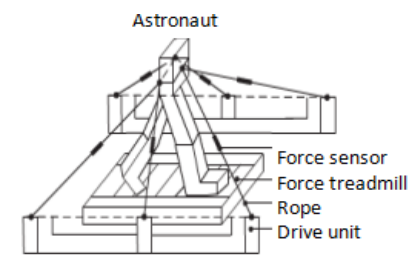

(A)

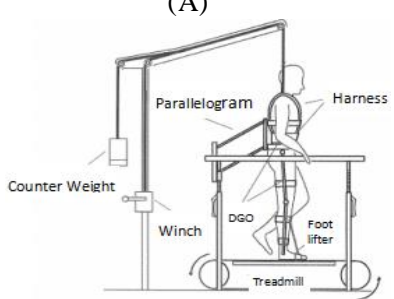

(C)

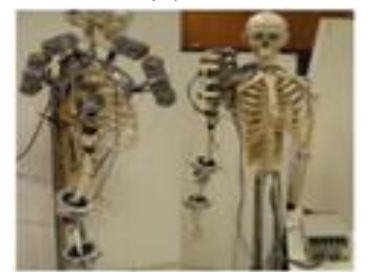

(E)

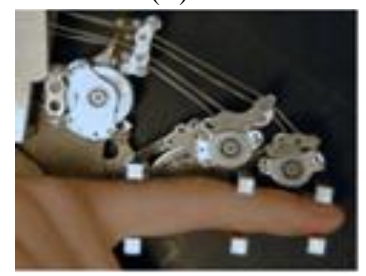

(G)

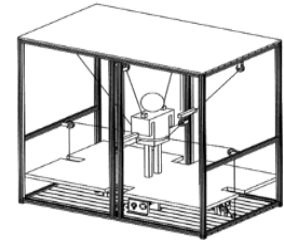

(B)

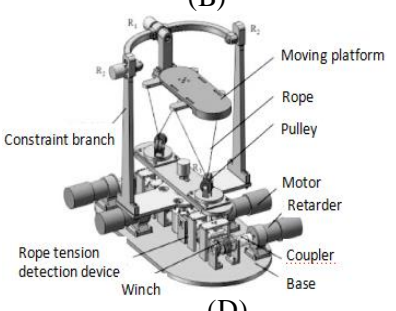

(D)

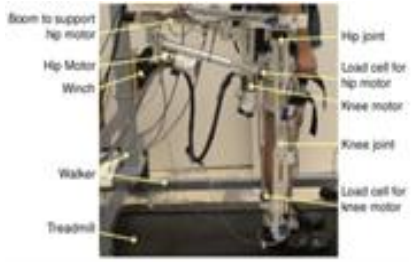

(F)

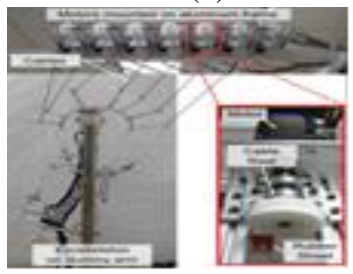

(H)
FIGURE II. EXAMPLES OF CABLE-DRIVEN REHABILIT ATION ROBOT S: (A) AST RONAUT TRAINING ROBOT. (B) PELVIC REHABILITATION ROBOT. (C) TRAINING ROBOT. (D) ANKLE REHABILITATION ROBOT. (E) UPPER ARM EXOSKELETON. (F) ALEX. (G) FINGER EXOSKELOTON (H) UPPER ARM EXOSKELITON

Although the research and application of the cable-driven rehabilitation robot has achieved considerable effects, there are still some problems should be considered: 1)the demand for the crowd should be broadened, improving the parallel recovery robot's automation degree and simplifying the operation process 2) rehabilitation robots' structure should be diversified, different patient or hurt levels need different mechanical structure; 3)rehabilitation cycle is long, more efficient cure method and rehabilitation structure should be presented. The popular and practical application of rehabilitation training equipment is still very difficult, the multi-functional integration or modularization is a new research direction.

\section{Review of Cable-driven Lifting Robots}

Hoisting equipment is an important tool to realize mechanization of material handling, and has been widely used. In recent years, materials should be carried have the trend towards large-scale, heavy-weight and increasingly complex hoisting environment, so lifting equipment is put forward higher and higher requirements. The flexible driving robot has simple structure, large working space, high modularity, easy dis as sembly and reorganization, high load capacity, fast moving 
speed and high cost performance. So, cable-driven lifting robot will be mainstream in the lifting equipment.

To solve the loading and unloading problem of large-scale port containers, Pennsylvania State University developed a cable array robot with three or four rope hoisting cargoes (Fig.III A), and analyzed the kinematic equation, kinetic model and synovial controller of the system. It has simple structure, light weight, high carrying capacity [22], etc. A 6 - DOF complete constrained cable-driven parallel robot (Fig.III B) is proposed and its motion is controlled by nonlinear positive feedback control strategy. The experimental results show that the control strategy of the optimal tension distribution can achieve the predetermined trajectory and reduce the energy consumption of the manipulator [23]. Jiayi HUANG [24] designed and produced a three-degreeof-freedom cable-driven outer space plane handling robot (Fig.III C). The kinematics model of the robot is established, and the corresponding model is solved by Matlab. The results show that the length of the cable is continuously changed along the trajectory, which can ensure the moving robot runs smoothly and continuously.

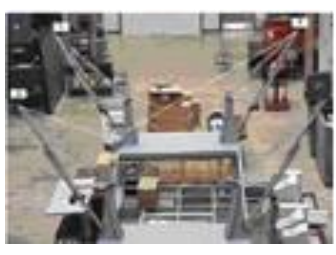

(A)

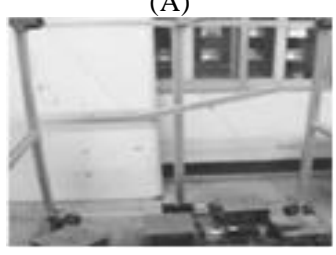

(C)

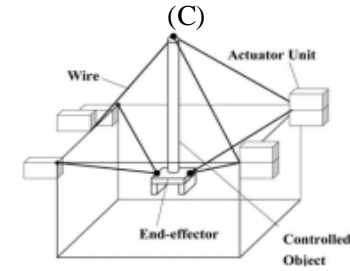

(E)

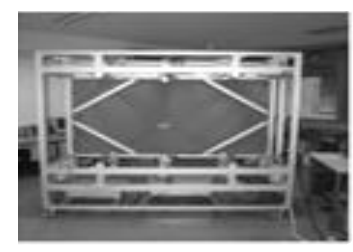

(B)

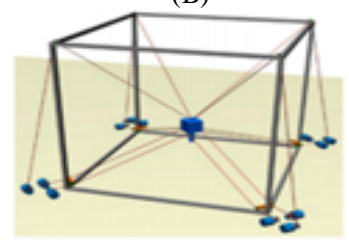

(D)

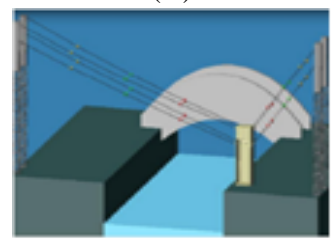

(F)
FIGURE III. EXAMPLES OF CABLE-DRIVEN LIFTING ROBOT S: (A) NIST ROBOCRANE. (B)SEGEST A MANIPULATOR. (C)SPACE HANDLEING ROBOT. (D)C4 ROBOT. (E)CR SYST EM. (F) CISIMO.

University of Ohio Bosscher [25] put forward a novel flexible cable-driven construction system (Fig.III D). This system can transport large-scale construction materials rapidly. Japan's Fukuoka University of Technology Kino et al [26] designed a 6-DOF flexible cable-driven lifting system(Fig.III E).The mechanism is driven by six cables, through the rodshaped end of the actuator to avoid the relaxation of the cable effectively, and realize high-precision lifting. Granicio University and Southern Lazio University designed a large space cable hoisting system(Fig.III F), which is suitable for suburban environments. The deformation and elasticity of the rope are considered, and the numerical simulation analysis of static and dynamic is carried out. Compared with other types of devices, the system's installation and disassembly is simpler, less impact on the surrounding environment [27].

\section{Review of other cable-driven robots}

Except the aforementioned cable-driven robots, the cabledriving technology has been extensively used in many other fields. In the 1980s, Landsberger [28] first proposed cabledriven parallel robot, and designed a three degree-of-freedom cable-driven parallel robot (Fig.IV A), and applied it to marine operating. As one of the major scientific projects in China's "Eleventh Five-Year Plan ", FAST program is controlled by six cables with 6-DOF cabin to track radio source's movement(Fig.IV B) [29] Fumiaki Takemura et al. [30] applied cable-driven parallel mechanism to the urban earthquake disaster personnel search and information collection, and developed the air balloon robot (Fig.IV C). Yongde ZHANG et al. [31] inspired by spider's pulling the silks to achieve movement, designed a cable-driven glass curtain wall cleaning robot (Figure 3-26). This cleaning robot is safer and reliable, with light weight, high efficiency and cost-effective features. Yaqing ZHENG et al. [32] designed a set of cable-driven parallel robot (flying carpet) (Fig.IV D), which can be used to repair the 10,000-ton steel ship. They focused on the design of main layout, and discussed its automation control strategy and development trend. It's the first time to carry out the work of space, structure, control and other related research in China. Yu YAO [33] proposed a 3-DOF pure rotary wind force measuring device based on five flexible cables (Fig.IV F). The device has simple structure, fast response speed.

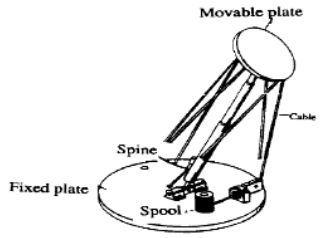

(A)

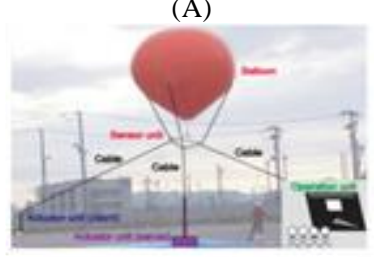

(C)

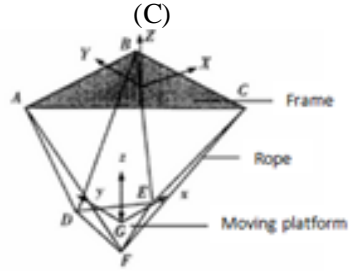

(E)

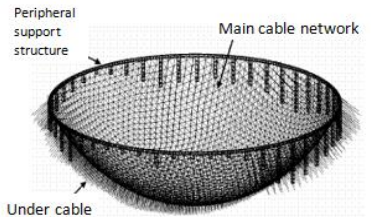

(B)
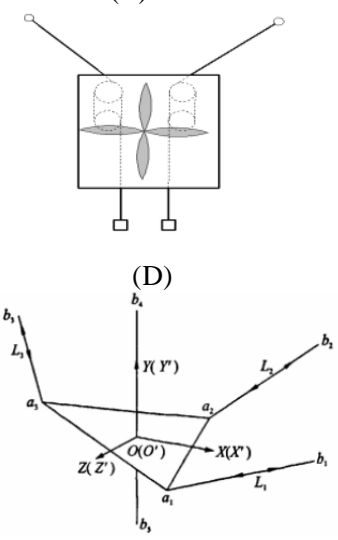

(F)
FIGURE IV. EXAMPLES OF OTHER CABLE-DRIVEN ROBOT S: (A) PARALLEL PLATFORM TELESCOPE. (B)FAST RADIO (C) BALLNOON ROBOT (D) GLASS CLEANING ROBOT . (E)B6 DEGREES OF FREEDOM PARALLEL ROBOT. (F) THE SCHEMATIC DIAGRAM OF THE MACHINE BODY PIECES. 


\section{RESEARCH ON CABLE TENSION TECHNOLOGY}

The manipulator transports power and movement through the cable, and the winding method in the chain is often different according to the different movement requirements. The cable tension mechanis m robot can generally divided into incomplete constraint positioning mechanis $m$, fully constrained positioning mechanis $m$ and over-constrained positioning mechanis $m$ [34]. So the tension of the cable determines whether the prepositioning can be achieved and the work requirements can be met. Furthermore, the appropriate tension can ensure the stability and movement accuracy.

There are some researches on cable tension technology, but not deep and comprehensive. Chaoqun WANG et al. [35] use spring devices to tension the rope in the design of five fingers dexterity (Fig.V A). This tension device is simple, through changing the number of spring or stiffness of spring to achieve different tension. However, the stretchability of cable affects the accuracy and stability when the robot arm grabs heavier objects. Weihai CHEN [36] used a more rigid steel cable, but in order to avoid impact in movement process, and added a short spring in cable to simulate the flexible rope characteristics (Fig.V B). Mean while they press the cable on guide wheel, so the force can be measured by the tension value sens or behind the guide wheel. It's easy to observe and adjust the force during the movement. Zhilong LIU et al. [37] designed a cable tension mechanism (Fig.V C), through a screw guide rod to pull the cable, and the cable can maintain a certain tension. Guide rod can maintain smooth and equal movement. The small tension changes of cable can be accurately demonstrated through the rise and fall of the guide bar. Xiuhua SUI designed an automatic hydraulic tensioning mechanism (Fig.V D) [38] when studying the tensioning mechanism of the belt conveyor. This tensioning mechanis m can run smoothly during start and stop process, and can meet the requirements of long-distance.

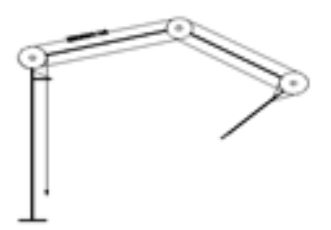

(A)

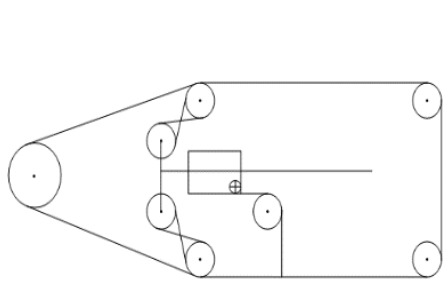

(C)

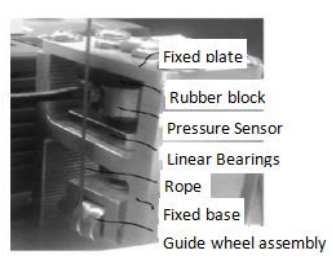

(B)

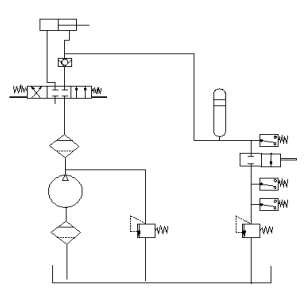

(D)
FIGURE V. EXAMPLES OF CABLE TENSION TECHNOLOGY: (A) TENSION REPLY MACHANISM DIAGRAM. (B)TENSION TEST INGSYSTEM. (C)BILATERAL TENSIONINA MACHANISM. (D) HYDRAULIC TENSION SYSTEM.

\section{MODELING Methods OF CABLE-DRIVEN RoBOTS}

Because of the non-linearity, multi-degree of freedom, strong coupling and time-varying characteristics of parallel robot, establishing a good dynamic model is always an important part of the study. Modeling and movement analys is of the robot are the theoretical basis for the robot design, simulation, error analysis and compensation, motion path planning and control system design etc. Fast and accurate robot motion modeling analysis is a key issue to improving the robot kinematic performance [39]. The motion simulation uses the computer visualization and object-oriented means to simulate the dynamic characteristics of the robot, thus solving the problems in the process of robot design, manufacturing and operation, and avoiding the possible accidents and unnecessary losses caused by the direct operation [40]. In fact, the difficulty of modeling the cable traction mechanism lies in the modeling of the cable.

Bo ZHANG [41] used Newton-Eule method to establish cable-driven parallel robot dynamics model, and adopted seriesconstrained/parallel-drive principle, so that the body can achieve the function which the general cable-driven mechanism can't realize. Shiang et al. [42] used Lagrange equation and hypothetical modal method, processed the cable into a nonquality linear model, and established a 3-DOF array robot dynamics model. Xin SUN et al. [43] fully analyzed the properties of the suspension cable in the FAST project, and divided the cable into discrete flexible shaft element, established the dynamic model, and analyzed rigid displacement, elastic deformation and manipulate force considering the self-weight and inertia force. Zhipeng LI et al. [44] adopted parameters optimization design to solve structure flexibility problem of the high precision flexible cable traction parallel robot and verified the accuracy of the optimal design. Jing chao WEN [45] adopted ADAMS to test the six-DOF parallel robot, and the dynamic equation was deduced by Lagrangian method to study its tracking effect. Pan LIU [46] adopted the Newton Euler to build dynamic model in the study of cable-driven rehabilitation robot, and solved the interference of positioning accuracy because of the cable's deformation.

\section{MOTION CONTROL ANALYSIS OF CABLE-DRIVEN ROBOTS}

Robot control technology is an important field in robotics research. In cable-driven parallel robot, trajectory tracking is one of the key points of control. Through the calculation of control algorithm determines the variables of each cable, then sends it to the cable manipulating device, through combination with each cable to synthesize a final effect. The high nonlinearity and uncertainty of cable-driven parallel robot makes the trajectory tracking control difficultly [47]. The different application areas and requirements also determine different combination forms of robot configuration.

Qi LIN et al. [48] built a controlexperimental platform when studying cable-driven parallel mechanism, according to the specified amplitude and frequency of single-degree-of-freedom oscillation control, and combined with the test results to analyze the error. When studying large-scale radio teles cope, the error of cabin model is regarded as external disturbance by Hong BAO [49]. Self-deactivating slip mode controller has multi-input and multi-output. Bin ZI [50]based on the analysis of the system characteristics such as the high non-linear dynamics model, uncertainty parameters and external disturbance, proposed a new method of combining the conventionalPI control with the Fuzzy 
control to achieve high-precision trajectory tracking. This control method has the characteristics of fast dynamic response and steady state precision. Zhicheng QIU [51] lists the corresponding switching function to determine the sliding surface in the study of flexible manipulator, and adopts the PPF and PD compound control method, which greatly improves the attenuation rate and can quickly and effectively suppress the vibration.

\section{THE DEVELOPMENT TREND OF CABLE-DRIVEN ROBOT S}

\section{A. Modularization and Integration of the Actuator}

Traditional cable-driven robots can just achieve a single and limited function, such as rehabilitation robots, lifting equipment etc. And this mechanical equipment has large base, controller and other ancillary devices, to some extent, which increased space and manufacturing costs. Especially in the field of aerospace, the astronauts need to carry out a number of rehabilitation training, so it's not realistic if the limited space is occupied by a large number of layouts. Some scholars put forward multi-mode cable-driven rehabilitation training robot integrated with running training, bench press training and weight squat and some other kinds of training projects, which can save space and overall cost [52].

\section{B. Hybrid Drive with Multiple Driving Modes}

Cable driving has a variety of unique advantages, but there are some inherent shortcomings, which make a single drive in some specific occasions can't meet the work needs well. Hybrid drive can effectively incorporate the advantages of a variety of drive methods to achieve the best results. For example, in minimally invasive surgery, the traditional interventional catheter device lacks initiative and versatility, the researchers combined memory alloy with cable driving technology together, providing a new study direction to solve complex and timeconsuming operation process [53]. Hybrid driving parallel robot has the characteristics of simple structure, high degree of modularity, low speed and low price, so it can not only operate with high precision, high efficiency and large load, but also has more flexible output, can be quick and convenient to change the output movement [54].

\section{Application of Precision Cable Driving Technology}

In modern military reconnaissance, medical instrument, aerospace, mechanical arm and many other areas require sophisticated transmission. Precision cable transmission based on the principle of flexible transmission, which regards cable as transmission medium, through the static friction between the master and slave wheel to transmit torque, and can avoid gaps, friction and other non-linear factors. Precision pointing organization has a good application prospect [55]. Compared with traditional gear drive, chain drive, belt drive and other transmis sion methods, precis e cable driving has high rigidity, no friction, low return stroke, no lubrication, environmental adaptability, high transmission ratio, transmission smoothly, high efficiency, low manufacturing as sembly requirements, light weight and easy to maintain. High precision driving will also be a hot area in the study of cable driving technology.

\section{Exploring New Materials for the Cable}

Cable is a key part of the cable driving technology, its performance directly affects the working ability and stability of the equipment. Traditional cable-driven robots use wire rope, nylon rope, and so on. These materials can meet some requirements, but still have large quality, poor wear resistance, poor corrosion resistance, poor fatigue and other shortcomings. In Rio Olympic Games, there was an unfortunate event that the cable-driven camera robot falling down and hit the audience because of cable's break. To ensure the stability and reliability, it is necessary to develop more suitable driving cable actively after optimizing the equipment structure, which is significant to enhance the performance of the whole equipment.

\section{CONCLUSION}

Cable-driven robots has many advantages, and its in-depth research has broadened market and application value. At present, researches on the cable-driven machine include work space, positioning accuracy, structural design, stiffness analysis and control system, etc. With the development of new and highaggregate materials, study about material, shape, and durability and tensile strength of cable should be considered in future. Cable driving technology used in precision transmission is also a new research field. Meanwhile, combining cable driving with rigid transmission coordinately, and developing a hybrid manipulation robot with diverse function, strong adaptability, large bearing capacity and good durability is necessary.

\section{ACKNOWLEDGMENT}

This work was supported by Special Cooperation Program for Higher Education Institutions Collaborative Innovation (Grant No.KH2016006), Graduate research and innovation foundation of Chongqing (Grant No.CYS17020), Graduate research and innovation foundation of Chongqing (Grant No.CYS17021), Basic Science and Advanced Technology Foundation of Chongqing (Grant No.cstc2016jcyjA0472), Frontier Science \& Technology Innovation Project (Grant No.17-163-11-ZT-005-011).

\section{REFERENCES}

[1] Beltzner, Dale. "Remote-Control Robot". Scholastic Dynamath (2008).

[2] F. Xu. "Cable-driven robot arm's innovation design and research". Diss. China Ocean University, 2014.

[3] K. Yueyang. "Study on Modeling and Path Planning of Cable-driven Active Catheters". Diss. Nanjing University of Aeronautics and Astronautics, 2014.

[4] C. Feng, and W. Chenyao. "Overview of the study of the operation of robot." Mechanical design 26.6(2009): 1-2.

[5] L. Peng. "Robust mechanics analysis and stability evaluation of cablepulling parallel manipulator". Diss. Xi'an University of Electronic Science and Technology, 2015.

[6] Y. Liangliang. "Analysis of the motion characteristics of cable-driven Camera". Diss. Xi'an University of Electronic Science and Technology, 2012.

[7] Cone, Lawrence L. "Skycam: An Aerial Robotic Camera System." 1985.

[8] Brooks, Andrew, et al. A High-Performance Camera Platform for RealTime Active Vision. Field and Service Robotics. Springer London, 1998:527-532.

[9] Sutherland, Orson, et al. "Tracking With Hybrid-Drive Active Vision." 2000. 
[10] Truong, Harley, S. Abdallah, and S. Rougeaux. "A Novel Mechanism for Stereo Active Vision." Australian Conference on Robotics \& Aut omation2000.

[11] http://www.camcat-systems.com/home/[DB/OL].2017.9

[12] Y. Feng, and C. Qiang. "Overview of the development of foreign cableway camera system." Modern Television Technology 7 (2015): 8288.

[13] http://www.cablecam.se/cabledolly.php[DB/OL].2017.9

[14] S. Yu, Y. Qiu, and P. Liu. "Optimal Cable Tension Distribution of the High-Speed Redundant Driven Camera Robots Considering Cable Sag and Inertia Effects." Advances in Mechanical Engineering 2014.4(2014):1-11.

[15] Z. Lixun, L. Pan, and W. Keyi. "Virtual gravity control of astronauts training robot based on ropetraction." Robot 32.4 (2010): 454-458.

[16] W. Weidong et al. "Analysis of the rope-driven parallel rehabilitation robot." Mechanical design and manufacturing engineering 41.11 (2012): 31-35.

[17] Colombo, G, et al. "Treadmill training of paraplegic patients using a robotic orthosis." Journal of Rehabilitation Research \& Development 37.6(2000):693.

[18] Y. Runtian, F. Yuefa, and G. Sheng. "Design and motion performance analysis of rope-driven ankle joint rehabilitation mechanism" Robot 37.1 (2015): 53-62.

[19] Banala, S. K.et al. "Robot assisted gait training with active leg exoskeleton (ALEX)." IEEE Transactions on Neural Systems \& Rehabilitation Engineering A Publication of the IEEE Engineering in Medicine \& Biology Society 17.1(2009):2-8.

[20] Jones, Christopher L., et al. "Design and Development of the Cable Act uated Finger Exoskeleton for Hand Rehabilitation Following Stroke." IEEE/ASME Transactions on Mechatronics 19.1(2014):131-140.

[21] M. Ying, and S. K. Agrawal. "A cable driven upper arm exoskeleton for upper extremity rehabilitation." IEEE International Conference on Robotics and Aut omation IEEE, 2011:4163-4168.

[22] Lytle, Alan M., et al. "Adapting a tele-operated device for autonomous control using three-dimensional positioning sensors: experiences with the NIST RoboCrane " Aut omation in Construction 13.1(2004):101-118.

[23] F. Shiqing, et al. "Motion control of a tendon-based parallel manipulator using optimal tension distribution." IEEE/ASME Transactions on Mechatronics 9.3(2004):561-568.

[24] H. Jiayi et al. "Research on flexible cable driven space capsule handling robot." Mechanical science and technology 31.11 (2012): 1748-1753.

[25] Bosscher, Paul, et al. "Cable-suspended robotic contour crafting system." Aut omation in Construction 17.1(2008):45-55.

[26] Kino, Hithoshi, et al. "Sensorless Position Control Using Feedforward Internal Force for Completely Restrained Parallel-Wire-Driven Systems." IEEE Transactions on Robotics 25.2(2009):467-474.

[27] Colombo, G, et al. "Treadmill training of paraplegic patients using a robotic orthosis." Journal of Rehabilitation Research \& Development37.6 (2000):693.

[28] Landsberger, Samuel E., and T. B. Sheridan. "A Minimal, Minimal Linkage: The Tension-Compression Parallel Link Manipulator." Robotics Mechatronics \& Manufacturing Systems (1993):81-88.

[29] L. Hui, et al. "Preliminary Running and performance Test of the Huge Cable Robot of FAST Telescope." (2018).

[30] Enomoto, Masaya, et al. "1P2-S-095 Construction of balloon type cabledriven robot system for information collection at major disaster(Rescue System and Rescue Engineering 3,Mega-Integration in Robotics and Mechatronics to Assist Our Daily Lives)." European Journal of Physics36 (2015):14-16.

[31] Z. Yongde et al. "Development and experimental study of flexible cabledriven glass curtain wall cleaning robot" Journal of Instrumentation 34.3 (2013): 494-501.

[32] Z. Yaqing, and W. Jianpo. "Design of Rope Traction Parallel Robot for Improving Ship Repair Efficiency." China Ship Repairing 22.1 (2009): $11-15$.
[33] Y. Yu, W. Hongtao. "Electronic Jacobian matrix of 3-DOF rotating cable driving wind tunnel mechanism". Journal of Nanjing University of Aeronautics and Astronautics 43.1 (2011): 75-78.

[34] Ming, A., and T. Higuchi. "Study on multiple degree-of-freedom positioning mechanism using wires (part 1) - Concept, design and control." Int. J. Japan Social Eng 1994.

[35] W. Chaoqun "The Design of the Rope-driven Five-finger Dexterous Hand." Journal of Shanghai Dianji University 15.5 (2012): 301-305.

[36] C. Wehai et al. "Analysis of tension-constrained working space of ropedriven parallel robot." Journal of Beijing University of Aeronautics and Astronautics 37.7 (2011): 817-821.

[37] L. Zhilong. "Study on Tension System of Reciprocating Thread Cutting Machine". Diss. West ChinaUniversity, 2010.

[38] S. Xiuhua, X. Linjing, and M. Dejun. "Research and Analysis of Tensioning Mechanism of Mine Belt Conveyor with Adaptive Performance." Coal Mine Machinery 29.12 (2008): 52-53.

[39] T. Rongcheng, Xu Ying. "Robot movement analysis automatic modeling" journal of Tianjin university (natural science and en gineering technology edition) 4(1993):37-44.

[40] W. Mingke. "Research on Motion Simulation of Six - link Robot Motion Trajectory". Diss. Journal of Northeastern University, 2008.

[41] Z. Bo, Zhao Mingyang, L. Jin. "Study on the Dynamics of a 6 - DOF Cantilever Parallel Manipulator". Mechanical Science and Technology. 23.6 (2004): 735-738.

[42] Shiang, Wei Jung, D. Cannon, and J. Gorman. "Optimal force distribution applied to a robotic crane with flexible cables." IEEE International Conference on Robotics and Automation, 2000. Proceedings. ICRA IEEE, 2000:1948-1954 vol.2.

[43] S. Xin, Q. Yuanying, and D. Baoyan. "Study on Driving Force of Suspension Feeding System of Large Radio Astronomical Telescope". Journal of Applied Mechanics 19.4 (2002): 80-84.

[44] L. Zhipeng, G. Yanling. "Design of planar parallel robot structure based on soft body dynamics analy sis" Mechanical design 23.7 (2006): 19-21.

[45] W. Jingzhao. "Research of parallel robot model and control strategy". Diss. Wuhan University of Technology, 2012

[46] Liu Pan et al. "Dynamics and modeling of cable-driven rehabilitation robot." Journal of Harbin Engineering University 30.7 (2009): 81 1-815.

[47] G. Dingwei, L. Yanyang, L. Hongwei. "Study on Joint Softening Control of Rope Traction Parallel Robot". Computer Knowledge and Technology: Academic Exchange 12.9 (2016): 246-249.

[48] L. Qi, B. Liang, and Y. Zheng. "Control on model attitude and oscillation by wire-driven parallel manipulator support system for low-speed wind tunnel." Journal of Experiments in Fluid Mechanics (2008).

[49] B. Hong. "Controlling, optimization and experiment of feed point pointing system for large radio telescope". Diss. Xidian University, 2005.Journal of Xidian University (Natural Science Edition)

[50] Z. Bin, Z. Zhen cai, D. Jingli. "Study on Motion Control of Cable-Driven Parallel Robot". Vibration and Shock 28.9 (2009): 48-51.

[51] Q. Zhicheng. "Active vibration control of rigid-flexible coupling sy stem". Chinese Journal of MechanicalEngineering, 2006, 42 (11): 26-33.

[52] K. Xiangfei. "Design and Control of ParallelRehabilitation Device Driven by Flexible Suspension". Diss. Jilin University, 2017.

[53] Z. Jian. "Study on the Intervention of Active Catheters Based on SMA and Rope Hybrid Drive". Nanjing University of Aeronautics \&amp; Astronautics, 2014.

[54] D. Yigang et al. "Kinematics Analysis and Simulation of a Hybrid Rope Drive Robot." Journal of System Simulation 19.17 (2007): 4007-401 1.

[55] L. Yafei. "Study on Mechanism and Design Method of Precision Cable Propulsion Transmission". University of National Defense Science and Technology.2013 